\title{
Col1a1+ perivascular cells in the brain are a source of retinoic acid following stroke
}

\author{
Kathleen K. Kelly ${ }^{1}$, Amber M. MacPherson ${ }^{1}$, Himmat Grewal ${ }^{2}$, Frank Strnad ${ }^{2}$, Jace W. Jones ${ }^{3}$, Jianshi Yu ${ }^{3}$, \\ Keely Pierzchalski ${ }^{3}$, Maureen A. Kane ${ }^{3}$, Paco S. Herson ${ }^{2,4,5}$ and Julie A. Siegenthaler ${ }^{1^{*}}$
}

\begin{abstract}
Background: Perivascular stromal cells (PSCs) are a recently identified cell type that comprises a small percentage of the platelet derived growth factor receptor- $\beta+$ cells within the CNS perivascular space. PSCs are activated following injury to the brain or spinal cord, expand in number and contribute to fibrotic scar formation within the injury site. Beyond fibrosis, their high density in the lesion core makes them a potential significant source of signals that act on neural cells adjacent to the lesion site.
\end{abstract}

Results: Our developmental analysis of PSCs, defined by expression of Collagen $1 \mathrm{a} 1$ in the maturing brain, revealed that PSCs first appear postnatally and may originate from the meninges. PSCs express many of the same markers as meningeal fibroblasts, including expression of the retinoic acid (RA) synthesis proteins Raldh1 and Raldh2. Using a focal brain ischemia injury model to induce PSC activation and expansion, we show a substantial increase in Raldh1+/ Raldh2+ PSCs and Raldh1+ activated macrophages in the lesion core. We find that RA levels are significantly elevated in the ischemic hemisphere and induce signaling in astrocytes and neurons in the peri-infarct region.

Conclusions: This study highlights a dual role for activated, non-neural cells where PSCs deposit fibrotic ECM proteins and, along with macrophages, act as a potentially important source of RA, a potent signaling molecule that could influence recovery events in a neuroprotective fashion following brain injury.

Keywords: Pericyte, Perivascular stromal cell, Retinoic acid, Stroke, Brain fibrosis, Meninges

\section{Background}

Following CNS injury, the initial, local cellular response is protective, confining the injury and preventing extensive inflammation and neurodegeneration [7, 41], but large amounts of fibrosis and extracellular matrix (ECM) protein deposition can impede neuronal repair $[8,46]$. Pericyte-like cells termed perivascular stromal cells (PSCs) or type "A" pericytes have been identified as a major source of ECM proteins that generate the fibrotic scar, separate from the well-characterized astroglial scar, within the injured CNS tissue following both spinal cord and stroke injury $[9,11,31,48]$. Beyond their role in fibrotic scar formation, however, PSCs in the lesion core are uniquely

\footnotetext{
*Correspondence: julie.siegenthaler@ucdenver.edu

${ }^{1}$ Department of Pediatrics, Section of Developmental Biology, University of Colorado Denver-Anschutz Medical Campus, 12800 E. 19th Ave MS-8313, Aurora, CO 80045, USA

Full list of author information is available at the end of the article
}

positioned to interact with a variety of resident (glia, neurons, microglia) and infiltrating inflammatory cell types in the days and weeks post-injury.

Despite the profound response of PSCs to brain injury and their role in fibrotic scar formation, much remains unknown about this cell type. A few unique and defining characteristics of PSCs have been reported. These include (1) expression of platelet derived growth factor receptor- $\beta$ (PDGFr $\beta$ ), but not the pericyte marker desmin and (2) they are labeled in GLAST-CreErt [11] and Collagen1a1-GFP (Col1a1-GFP) [48] transgenic mouse lines. It is not clear, however, if the cells labeled by the two transgenic mouse lines are the exact same cell population. That said, both lines label a subset of perivascular cells that are PDGFr $\beta+/$ desmin-negative and cells labeled by the two lines increase in number and fill the lesion core following spinal cord injury in a similar manner. In addition to lineage ambiguity, developmental characterization of PSCs is 
lacking and other, non-fibrosis functions for PSCs postinjury have not been identified.

Activity of the Col1a1 promoter (Col1a1-GFP) has previously been shown to identify PSCs in the spinal cord [48]. Here we use protein expression of Colla1 to identify PSCs and characterize the temporal and spatial distribution of Col1a1+ PSCs in the maturing brain. We observe that Colla1+ PSCs are largely absent in the early postnatal brain, but increase in number over the first three postnatal weeks. Initially, Col1a1+ cells are associated with vessels near the meningeal surface, but as their numbers increase so does their depth within brain regions. This information, along with the observation that Col1a1+ PSCs express many of the same markers as meningeal fibroblasts, suggests that Colla1+ PSCs may originate from the meninges during postnatal brain development. Meningeal fibroblasts express enzymes Raldh1 and Raldh2 required for synthesis of retinoic acid (RA), a hormone with diverse functions in the CNS including neurogenesis and cell survival. We find Colla1+ PSCs in the un-injured brain express both Raldh1 and Raldh2. This sets up the possibility that expansion of PSCs capable of RA synthesis within a brain injury site creates a source of RA that can act on cells within and adjacent to the injury. We tested this idea using a focal brain ischemia model in mice (middle cerebral artery occlusion or MCAO) which has previously been shown to lead to a substantial increase in PSCs within the lesion site [9]. Analysis of Raldh1 and Raldh2 expressing cells at day 7 post-injury revealed that in addition to numerous Raldh1 and 2-expressing PSCs, Raldh1 was expressed by macrophages within the lesion core. Consistent with an increase in Raldh1 and Raldh2 expressing cells, RA levels were significantly elevated in the ischemic hemispheres as was RA signaling in astrocytes and neurons in the peri-infarct region.

\section{Methods \\ Animals}

Wild type [postnatal day 0 (P0), P7, P14, P21 and 6 week (wk)] $\mathrm{C} 57 \mathrm{Bl} / 6 \mathrm{~J}$, were used throughout this study unless otherwise noted. RA signaling was assessed using the retinoic acid response element or RARE transgenic mouse line (RARE-hsp68-LacZ) [43] purchased from Jackson Laboratories. Strict adherence to The Recommended Guide for Care and Use of Laboratory Animals issued by the National Institutes of Health was performed using animal protocols approved by the Institutional Animal Care and Use Committee at The University of Colorado, Anschutz Medical Campus. All surgery was performed under anesthesia and suffering was minimized.
Tissue collection, immunohistochemistry and imaging

Animals were anesthetized with cryoanesthesia (P0) or $60 \mathrm{mg} / \mathrm{kg}$ pentobarbital $(\geq \mathrm{P} 6)$ followed by transcardiac perfusion initially with PBS to clear red blood cells then $4 \%$ paraformaldehyde. Whole brain tissue was isolated and incubated in $4 \%$ paraformaldehyde for $2 \mathrm{~h}, 20 \%$ sucrose overnight and mounted in Tissue Tek for cryosecting. Sections at $12 \mu \mathrm{m}$ were generated from fixed brain tissue and immunohistochemistry was performed as described in Zarbalis et al. [53] using the following antibodies: mouse anti-Colla1 1:100 (Sigma); rabbit anti-Col1 1:100 (Abcam); rabbit anti-PDGFrß 1:200 (Cell Signaling Technology); rat anti-PDGFr $\beta$ 1:200 (Novus Biologicals); rat anti-PDGFr $\alpha$ 1:200 (BD Bioscience); mouse anti-CoupTF2 1:300 (R\&D); rabbit anti-Raldh1 1:200 (Abcam); rabbit anti-Raldh2 1:400 (Sigma-Aldrich); mouse anti-CRABP1 1:100 (Abcam); rabbit anti-CRABP2 1:100 (Proteintech); mouse CD68 1:500 (Dako); rabbit anti- $\beta$-galactosidase 1:500 (MP Biomed); chicken anti- $\beta$-galactosidase 1:500 (Abcam); mouse anti-NeuN 1:500 (Millipore); rabbit anti-glial fibrillary acidic protein (GFAP) 1:500 (Sigma-Aldrich). Following incubation with primary antibodies, sections were incubated with appropriate Alexafluor-conjugated secondary antibodies (Invitrogen) at 1:500, Alexafluor 633-conjugated isolectin-B4 (Invitrogen) at 1:500 to label blood vessels and microglia [3], and DAPI (4',6-diamidino-2-phenylindole) to label nuclei (Invitrogen). The immunostained tissue sections were imaged using confocal imaging (Zeiss 780 LSM).

\section{Analysis of PSCs in postnatal and adult brain}

Sagittal sections of P0, P7, P14, P21 and adult (6-8 week old mice) brains were produced as described above and immunostained with Col1a1, IB4 and DAPI. Tile scan, $10 \times$ confocal images of the entire sagittal section of the brain at each time point were collected using a Zeiss 780 LSM and associated Zen software. Brain regions were analyzed using the Zen Blue software for (1) the number of vessels (defined by labeling with IB4) with Col1a1+ cells (as defined by DAPI+ nuclei) per area of a brain region (area: $\mathrm{cm}^{2}$ ) and (2) average distance of vessels surrounded by Col1a1+ cells from the pial surface (distance: $\mu \mathrm{m})$. Regions measured at each time point were the cerebral cortex, hippocampus, striatum, hypothalamus, thalamus, midbrain, hindbrain/cerebellum. We used the Allen Mouse Brain Atlas to define regional boundaries at each post-natal time point. For quantification of Raldh1 and Raldh 2 expressing cells in stroke brains at 7 days post-MCAO, $10,10 \times$ fields per brain at the level of the ischemic core were analyzed for the number of Raldh1+ or Raldh2+ cells. Individual cells with positive staining were defined by presence of DAPI+ nuclei. The ischemic 
core was defined by high density of IB4+ macrophages with amoeboid morphology. The number of positive cells was divided by the area analyzed $\left(\mathrm{mm}^{2}\right)$ to generate a cell density for each field and averaged across all images to generate a mean for each brain. For comparison, we analyzed the non-ischemic cerebral cortex in the opposite hemisphere for Raldh1+/DAPI+ and Raldh2+/ DAPI+ cell density in the same manner. To analyze the number of GFAP+ astrocytes and NeuN+ neurons with $R A R E-L a c Z$ transgene activity (defined by expression of $\beta$-galactosidase via antibody) in the non-ischemic cerebral cortex and peri-infarct region, we collected $20 \times$, 4-by-4 tile scan confocal images of the peri-infarct region and a corresponding region in the cerebral cortex of the opposite hemisphere. For each brain, 4 tile scan images were collected in each hemisphere and analyzed for the number of $\beta$-gal+/GFAP + and $\beta$-gal $+/ \mathrm{NeuN}+$ per area $\left(\mathrm{mm}^{2}\right)$. The peri-infarct region was defined by activated, GFAP+ astrocytes. For each time point and type of analysis, a minimum of 3 animals were used for analysis $(\mathrm{n} \geq 3)$.

\section{Middle cerebral artery occlusion (MCAO)}

MCAO animals were generated as described in Kelley et al. [20]. Briefly, adult male, wildtype C57Bl/6J or RARE-hsp26-LacZ/+ maintained on the ICR background (8-12 weeks old) mice were anesthetized and following baseline measurements of blood flow, unilateral MCAO was performed by inserting a 6.0 nylon monofilament into the internal carotid artery through a midline ventral neck incision. The filament was positioned for occlusion at $6 \mathrm{~mm}$ from the internal carotid/pterygopalatine artery bifurcation for $60 \mathrm{~min}$. After the occlusion period animals were removed from anesthesia and no pain relieving drugs were administered to prevent confounding of outcomes. Brain tissue was collected 7 days post MCAO as described for histology or analysis of retinoid and RA levels.

\section{RA quantification}

Non-injury or MCAO brains were hemisected and the cortex/striatum from the right and left hemispheres were harvested in low light conditions to prevent RA degradation, frozen separately and kept at $-80{ }^{\circ} \mathrm{C}$ until assayed. Tissue was homogenized and retinoids were extracted with a liquid-liquid extraction method for retinoids that has been described in detail previously [17]. RA was quantified by high performance liquid chromatography (HPLC)-multistage tandem mass spectrometry using a Fast HPLC-multiple reaction monitoring cubed $\left(\mathrm{LC}-\mathrm{MRM}^{3}\right)$ method [14]. Retinol and total retinyl ester were quantified by high performance liquid chromatography-ultraviolet detection (HPLC-UV) [16]. Results are given as mole retinoid per gram tissue and expressed as mean \pm SEM with $\mathrm{n}=2$ for each control brain hemisphere (right and left) and $n=3$ for each stroke brain hemisphere (right and left). Statistical significance was assessed using a two-tailed, unpaired Student's $t$ test (GraphPad).

\section{Statistics}

One-Way ANOVA and Student-Newman-Keuls post hoc analysis were used to assess statistically significant differences for PSC counts and distances. To address correlation between cell counts and distance, Pearson Correlation was performed. To detect statistically significant differences in mean values between two groups, Student $t$-tests were used. The standard error of the mean (SEM) is reported on all graphs.

\section{Results}

Temporal and spatial distribution of Col1a1+ PSCs in the early postnatal mouse brain

The Col1a1-GFP transgenic line has been used to identify a subset of perivascular cells that dramatically expand in number in response to a spinal cord injury [48] that have the same characteristics of PSCs described in stroke injury [9]. Therefore, Colla1 expression can be used to identify PSCs in the uninjured brain. Using an antibody to Col1a1, we observe Col1a1+ cells in the meninges surrounding the mouse brain (Fig. 1A, B, carets). Within the brain parenchyma at P7 and P21, we observe some large diameter vessels with Colla1+ cells surrounding them (Fig. 1A, B, arrows; arrows in $\mathrm{A}^{\prime}, \mathrm{B}^{\prime}$ insets indicate Colla1+/DAPI+ cells surrounding IB4+ blood vessel). We next characterized the spatial and temporal distribution of vessels with associated Col1a1+ PSCs from P0 to adulthood. We did not observe Col1a1+ PSCs at E16.5 in the developing embryonic brain (data not shown). At P0, vessels with Colla1+ cells were observed in the hippocampus, but very infrequently in all other brain regions analyzed (cortex, striatum, hypothalamus, thalamus, midbrain and hindbrain/cerebellum, Fig. 1C). PSC numbers in the hippocampus were reduced to the infrequent levels found in other brain regions at 1 week $(\mathrm{P} 7,1 \mathrm{C})$. As the postnatal vasculature and neural tissue continued to mature, there was an increase in Col1a1+ cell-associated vessels at 2 weeks in all brain regions (P14, Fig. 1C) followed by a fairly stable PSC cell population during the remainder of postnatal development and into adulthood (P21 and Adult, Fig. 1C). The increase in number of vessels with Colla1+ PSCs was significant for the cortex and striatum from P0 to adult (Fig. 1C, "p < 0.05) and for the hippocampus and hypothalamus from P14 (Fig. 1C, \#p < 0.05).

The majority of vessels with Col1a1+ cells at P7 were located near the meningeal surface of the brain (Fig. 1A, 

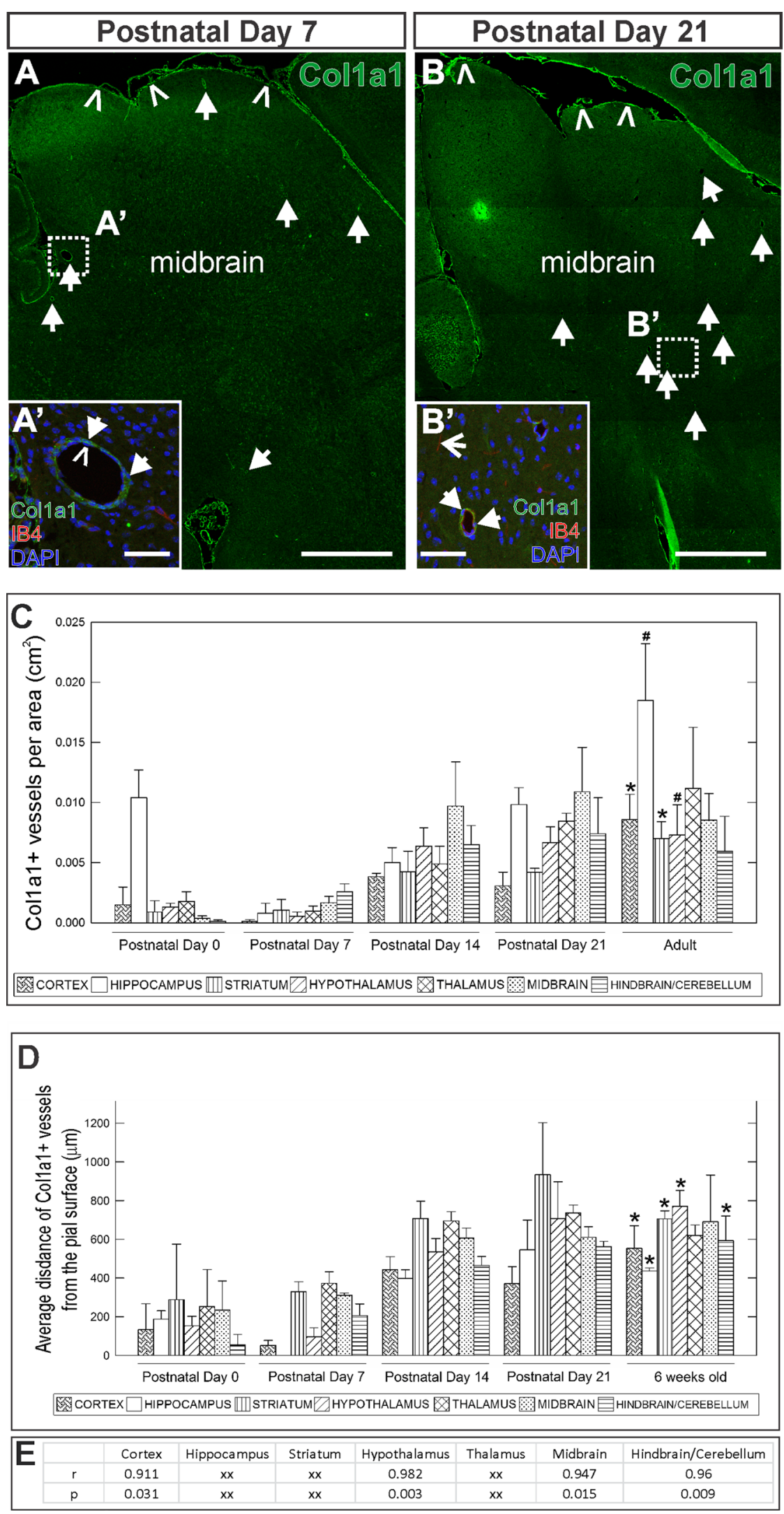
(See figure on previous page.)

Fig. 1 PSCs appear postnatally and increase in abundance and distance from meninges between P0 and adulthood. A, B Sagittal sections of P7 and P21 brain depicting Collagen-1a1 (Col1a1, green) PSCs (arrows) in the midbrain and in the meninges (carets). $\mathbf{A}^{\prime}$, $\mathbf{B}^{\prime}$ Higher magnification insets of large diameter, IB4+ vessels (caret indicates DAPI+ nuclei in the inner endothelium of the vessel) with Col1a1+ PSCs surrounding them (arrows). Open-arrow in $\mathbf{B}^{\prime}$ indicates small diameter IB4+ vessel, likely a capillary. C Graph depicting analysis of density of blood vessels with Col1a1+ PSCs for each brain area (cortex, hippocampus, striatum, hypothalamus, thalamus, midbrain and hindbrain/cerebellum) in P0, P7, P14, P21 and adult brain. Asterisks $\left(^{*}\right)$ mark significant differences between P0 and adult and \# symbols mark significant differences between P7 and adult. D Graph depicting scoring for the average distance from the pial surface of Col1a1+ PSC associated vessels per brain region (cortex, hippocampus, striatum, hypothalamus, thalamus, midbrain and hindbrain/cerebellum). Significant differences between P0 and adult are marked (*). E Table of significant Pearson Correlation Coefficients ( $r$ ) and associated $p$ values ( $p$ ) for PSC cell count and distance measurements shown in $\mathbf{C}$ and $\mathbf{D}$. In $\mathbf{C}$ and $\mathbf{D}, 3$ animals were scored at each time point with standard error bars. Scale bars $2 \mathrm{~mm}(\mathbf{A}, \mathbf{B})$ and $50 \mu \mathrm{m}\left(\mathbf{A}^{\prime}, \mathbf{B}^{\prime}\right)$

arrows), but as the Col1a1+ cell population expanded there appeared to be a corresponding increase in distance from the meningeal surface (Fig. 1B, arrows). To quantify this we measured the distance of Colla1+ PSC-associated vessels from the meningeal surface in all brain regions at P0, P7, P14, P21 and 6 weeks (Fig. 1D). We observed a relationship between developmental time progression and PSC distance from the pial surface in that the average distance from the pial surface increased over time in all brain regions (Fig. 1D). The correlation of cell number and distance from the pial surface was statistically significant for four of the seven brain regions scored (Fig. 1E). An increase in Colla1+ PSC distance from the pial surface might be the result of increasing CNS tissue around the PSCs due to brain growth or, possibly, Col1a1+ cells originate in the meninges and "enter" the perivascular space via arterioles and venules that penetrate the surface of the brain from the meningeal space. Consistent with this, Colla1-GFP+ PSCs are associated with large diameter arterioles and venules, structures which are physically linked to the meningeal surface, but not small diameter capillaries [48]. This analysis also reveals new distinctions between pericytes and vascular smooth muscle cells (vSMCs) and Col1a1+ PSCs in that the postnatal spatial and temporal expansion of Col1a1+ cells contrasts with that of pericytes/vSMCs that undergo expansion and spatial distribution during prenatal neurovascular development [2].

\section{PSCs dynamically express both pericyte and meningeal cell} markers

The positional analysis of Colla1+ cell distribution suggested that PSCs may originate from the meninges, thus we examined expression of meningeal cell markers within this population at P0 when PSCs are first observed in the mouse brain and in PSCs in the more mature brain at P21. We also examined expression of these markers in "activated" PSCs at 7 days post ischemic injury induced by 60 min MCAO.

PSCs co-express the population defining marker Col1a1 and PDGFr $\beta$ at both P0 (Fig. 2A, arrows), P21
(Fig. 2B, arrows) and in the lesion core (Fig. 2C, arrows). Transcription factor CoupTF2 (Fig. 2D-F, nuclear) was expressed by the Colla1+ meninges (Fig. 2D, carets) and by Col1a1+ PSCs at P0 (Fig. 2D, arrows), P21 (Fig. 2E, arrows) and in the stroke lesion by PDGFr $\beta+$ PSCs (Fig. 2F, arrows) but not by Ib4+ macrophages (Fig. 2F, carets). We assayed for PDGFr $\alpha$ expression, previously shown to be expressed by inactive and active PSCs [9, $11,48]$, and found that Colla1+ cells had weak PDGFro expression at P0 (Fig. 2G, open-arrows), but it was strongly expressed at P21 and in lesion PSCs (Fig. 2H, I, arrows). PDGFr $\alpha$ expression is noteworthy because this receptor is also expressed by some meningeal fibroblasts (see Fig. 2G, H, carets), again pointing to a possible meningeal origin of PSCs.

\section{PSCs express RA synthesis proteins and, along with macrophages, are a source of lesion-derived RA}

RA is a hormone with a variety of functions in the developing and adult brain [30]. Subsets of meningeal fibroblasts are one source of RA for the brain as they express enzymes required for RA synthesis [26, 45]. Our evidence points to a possible meningeal origin for Colla1+ PSCs, thus we looked at expression of RA synthesis enzymes Raldh1 and Raldh2 in Col1a1+ PSCs during postnatal development and in the 7 day post MCAO ischemic core. Raldh1 was expressed by some neurons in the postnatal brain as reported (Fig. 3A, arrows) [50] and by some Col1a1+ meningeal cells (Fig. 3A, carets) but not by Col1a1+ PSCs at P0 (Fig. 3A, open-arrows). At P21, however, we observed Raldh1 expression in Colla1+ PSCs (Fig. 3B, arrows). Within the ischemic core, CoupTF2+ PSCs expressed Raldh1+ however we observed CoupTF2+ PSCs that did not express Raldh1 (Fig. 2C, arrows, open arrows respectively). We observed that IB4+ cells with ameboid morphology, typical of macrophages/microglia that are present in large numbers in the lesion core at this time point [12, 47, 49], also expressed Raldh1 (Fig. 3C, carets). Raldh2, strongly expressed by the meninges, was also expressed by Col1a1+ PSCs at both P0 and P21, albeit very weakly 
Fig. 2 Expression of perictye and meningeal cell markers changes over maturation and post-injury activation of PSCs. Confocal images on sections from hippocampus (P0), thalamus or midbrain (P21) and cerebral cortex or striatum (MCAO) with antibodies that label pericytes and/or meningeal cells to characterize Col1a1+ PSC marker expression. Col1a1+ PSCs (green, A-C) express PDGFrß (red, A-C) at $\mathrm{PO}$ and $\mathrm{P} 21$ and in the post-MCAO lesion (arrows, $\mathbf{A}-\mathbf{C}$ ). At P0 and $\mathrm{P} 21, \mathrm{PDGFr} \beta$ is also expressed by perivascular pericytes that do not have Col1a1 expression (carets, A, B). CoupTF2 (red, D-F) is expressed by Col1a1+ (green, D, E) PSCs surrounding IB4+ blood vessels at PO and P21 (arrows, D, E) and by PDGF $\beta+$ PSCs (green, F) in the stroke lesion (arrows, $\mathbf{F}$ ). Carets in $\mathbf{D}$ indicate CoupTF2 +/Col1a1+ cells in the meninges. IB4 in $\mathbf{F}$ also labels macrophages (blue, caret). PDGFra is expressed in the meninges (red, carets, $\mathbf{G}, \mathbf{H}$ ), is weakly expressed by Col1+ PSCs at PO (green, open-arrows, $\mathbf{G}$ ) but is strongly expressed by these cells at P21 (arrows, $\mathbf{H}$ ) and in the stroke lesion (arrows, I). IB4 (b/ue) labels blood vessels and microglia/macrophages in A, D-H and DAPI (blue) marks nuclei in I. Scale bars $100 \mu \mathrm{m}$

at P0 (Fig. 3D, E, open-arrows and arrows mark PSCs and carets indicate meninges). Many, but not all, CoupTF2+ PSCs in the lesion core were also Raldh2+ (Fig. 3F, arrows mark some Raldh2+/CoupTF $2+$ cells and openarrows mark the CoupTF1+/Raldh2-negative cells). We did not assay for Raldh3 expression as it is not reported to be expressed by the meninges [40].

Cellular Retinoic Acid Binding Proteins-1 and 2 (CRABP1 and CRABP2) play a key part in RA signaling within a cell in that they bind RA and shuttle it to its nuclear hormone receptors [39]. CRAPB1 was not extensively expressed by Col1a1+ meninges or PSCs at P0 (Fig. 3G, carets and open-arrows respectively) though we did observe CRABP1 in Col1a1+ PSCs at P21 (Fig. 3H, arrows). CRABP1 was broadly expressed in the lesion core, co-localizing with PDGFr $\alpha+$ PSCs and other, unidentified cell types (Fig. 3I, arrows and carets, respectively). CRABP2 was expressed in the meninges (Fig. 3J, K, carets) at P0 and P21 but not in PDGFra+ PSCs (Fig. 3J, K, open-arrows). In the lesion, a subset of PDGFra+ PSCs co-expressed CRABP2 (Fig. 3L, arrows indicate PDGFr $\alpha+/$ CRABP2+ PSCs and open-arrows indicate PDGFr $\alpha+/$ CRABP2-negative PSCs).

Expression of RA synthesis enzymes (Raldh1 and Raldh2) indicates that cells in the ischemic lesion are a source of RA. We characterized this further by (1) colabeling sections from ischemic brains (60 min MCAO, 7 days post-injury) with antibodies to Raldh 1 and Raldh2 (Fig. 4A-C) and analyzing the density of Raldh1+ and Raldh2+ cells in the non-ischemic hemisphere versus the lesion core (Fig. 4E, F) and (2) quantifying RA levels in uninjured, non-ischemic and ischemic hemisphere at 7 days post $60 \mathrm{~min}$ MCAO (Fig. 4G). In nonischemic cerebral cortex, Raldh1/Raldh2 double positive
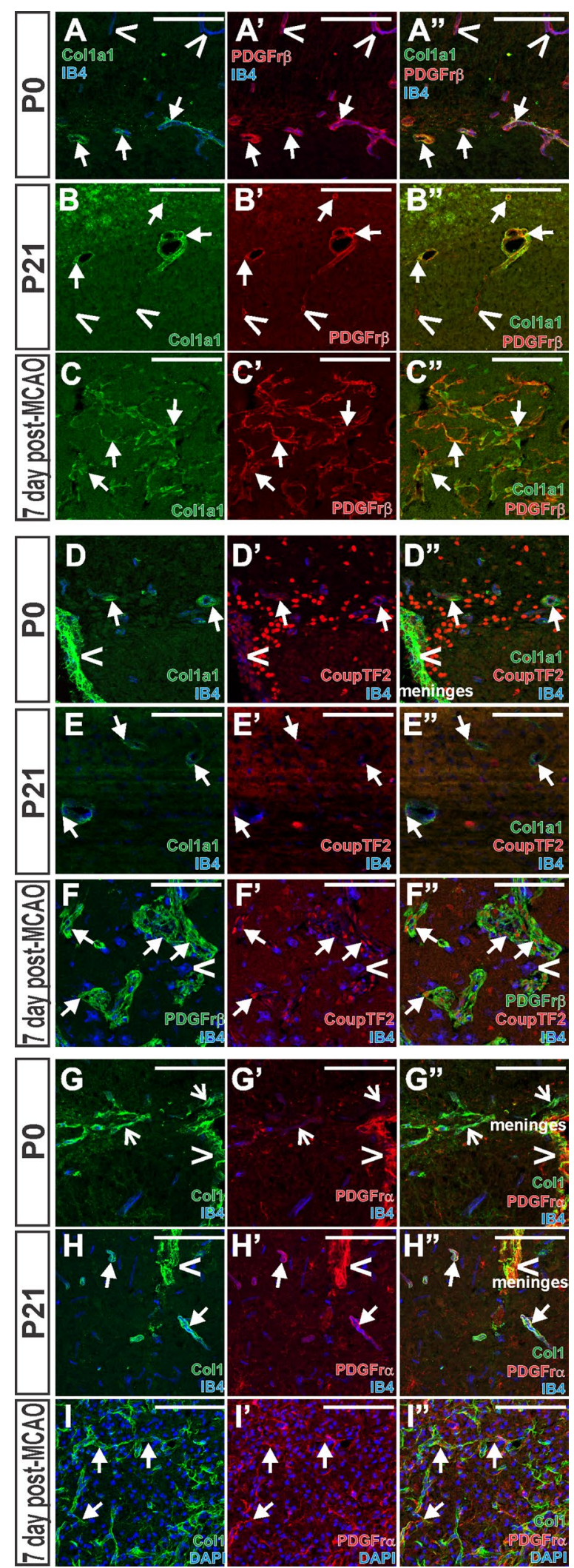

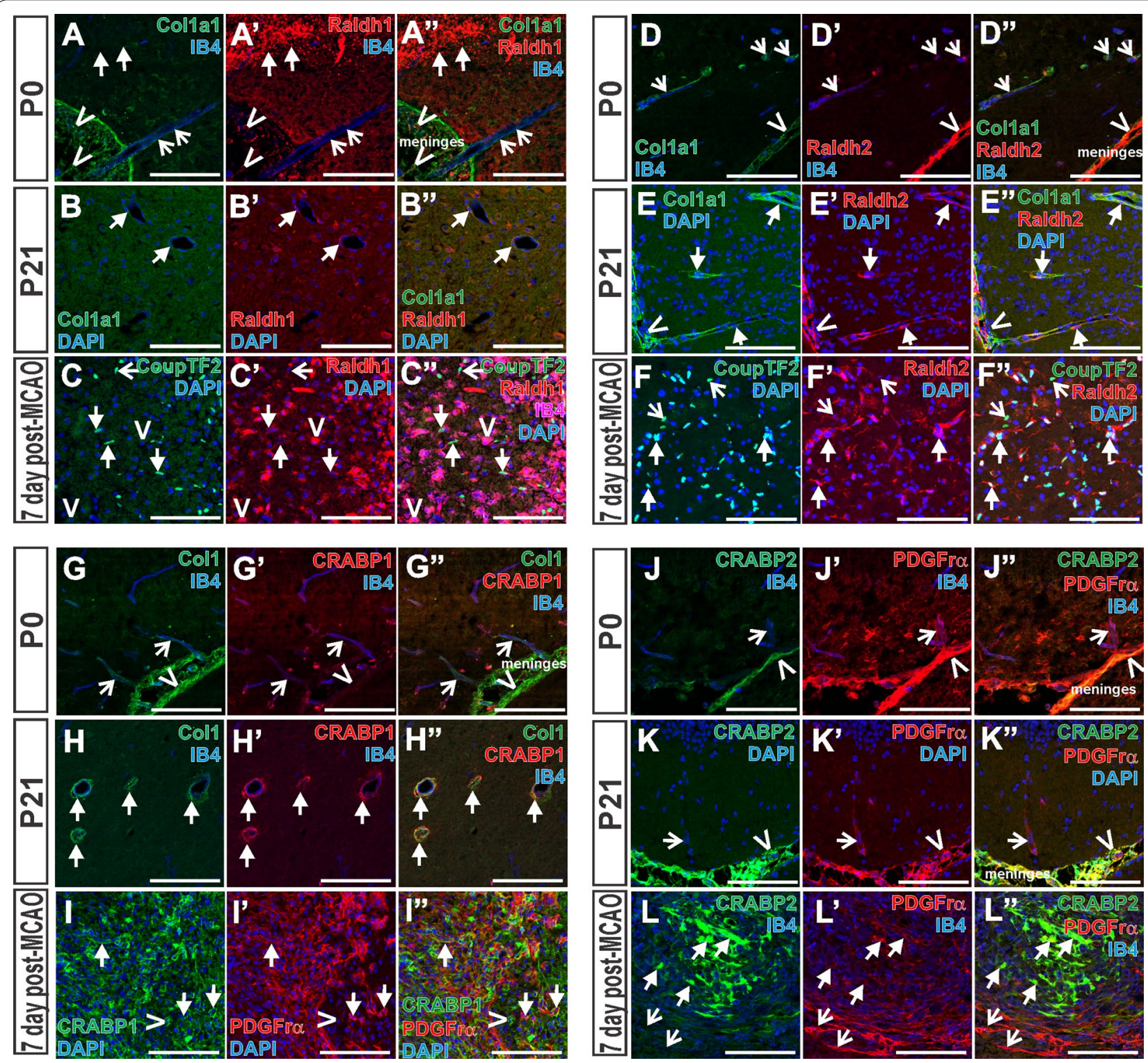

Fig. 3 PSCs express RA pathway proteins. RA biosynthesis protein Raldh1 (red) is not expressed by Col1a1+ PSCs at P0 (green, open-arrows in A) but is expressed by some cells in the meninges (carets in $\mathbf{A}$ ) and some neurons in the brain (arrows in A). At P21, Raldh1 (red, B) is expressed by Col1a1+ PSCs (green, B) surrounding blood vessels (arrows in B). In the stroke lesion, Raldh1 (red, C) is expressed in CoupTF2+ PSCs (green, arrows in C) and IB4+ macrophages (magenta, carets in C). Raldh2 (red, D, E) is expressed by Col1a1+ meningeal cells (green; carets in $\mathbf{D}$, E), is only very weakly expressed by Col1a1+ PSCs surrounding IB4+ vessels at P0 (open-arrows, D), but Raldh2 signal is strong in Col1a1+ PSCs at P21 (arrows in E). Following stroke, Raldh2 (red, $\mathbf{F})$ is expressed by CoupTF2+ PSCs (green, arrows in $\mathbf{F})$. Some CoupTF2+ PSCs in the lesion do not express Raldh1 or Raldh2 (open-arrows in C, F). CRABP1 (red, G) is not expressed by Col1a1+ (green, $\mathbf{G})$ meninges or PSCs at PO (carets and open-arrows, respectively in G) though is expressed by Col1a1+ PSCs (green, $\mathbf{H}$ ) surrounding IB4+ vessels at P21 (arrows in $\mathbf{H}$ ). PDGFra+ PSCs (red, I) in the stroke lesion express CRABP1 (green, arrows in $\mathbf{I}$ ) though there are other CRABP1-expressing cells in the lesion (caret in $\mathbf{I}$ ). CRABP2 (green, $\mathbf{J}, \mathbf{K}$ ) is expressed by PDGFra meninges (red, carets in $\mathbf{J}, \mathbf{K}$ ) but not by PDGFra+ PSCs (red open-arrows in $\mathbf{J}, \mathbf{K}$ ) at P0 or P21. CRABP2 (green, $\mathbf{L}$ ) is expressed by some PDGFra+ PSCs (red, arrows in $\mathbf{L}$ ) in the stroke lesion. Open-arrows in $\mathbf{L}$ indicate PDGFra+/CRABP2-negative cells. IB4 labels blood vessels and microglia/macrophages in $\mathbf{A}, \mathbf{C}, \mathbf{D}, \mathbf{G}, \mathbf{H}, \mathbf{J}$ and $\mathbf{L}$; DAPI (blue) marks nuclei in B, C, E, F, I, and $\mathbf{K}$. Scale bars $100 \mu \mathrm{m}$

PSCs were occasionally found in the perivascular space (Fig. 4A, carets). Within the ischemic core at 7 days post 60 min MCAO, the number of Raldh1+ and Raldh2+ cells was dramatically increased (Fig. 4B). Some Raldh1+ cells co-localized with Raldh2 (Fig. 4C, arrows) and these likely represent activated PSCs in the lesion core that express both Raldhs. Other Raldh1+ cells did not co-localize with Raldh2 and, as shown in Fig. 3C, these 
are macrophages. We further confirmed Raldh1 expression in macrophages by showing that Raldh1+ cells with ameboid morphology express the macrophage marker CD68 (Fig. 4D, carets) [36]. Raldh1+ (Fig. 4E) and Raldh2+ (Fig. 4F) cell density was significantly increased in the lesion core as compared to the contralateral, non-ischemic cerebral cortex $(\mathrm{p}<0.05)$. We next tested whether the ischemia-induced increases in Raldh expressing PSCs and macrophages elevated levels of RA in the ischemic hemisphere. RA levels were not significantly different between hemispheres from a non-injured brain and the non-injured left hemisphere (Fig. 4G) whereas the ischemic right hemisphere had significantly elevated levels of RA (Fig. 4E) ( $p<0.05)$. Additionally, retinol (vitamin $\mathrm{A}$, a precursor to $\mathrm{RA}$ ) as well as total RE (a storage form of vitamin A) were unchanged (data not shown), further supporting a change in production of RA due to elevated number of Raldh + cells in the lesion capable of synthesizing RA rather than an increase in available vitamin A. Collectively this data suggests that focal ischemia leads to elevated RA levels through injury-induced expansion of RA-synthesizing PSCs and macrophages.

To test whether elevated RA levels in the stroke hemisphere activate RA signaling following stroke, we used the RA activity reporter mouse line RARE-hsp68-LacZ [43] to look for sites of active RA signaling at 7 days post 60 min MCAO. Using an antibody to $\beta$-galactosidase ( $\beta$-gal) to detect activation of the RARE-LacZ reporter gene, we observed expression of the reporter in the hippocampus in both hemispheres (Fig. $5 \mathrm{~A} ; \mathrm{Hp}$ ) as has been described previously [10]. In the lesion hemisphere there was elevated reporter activity in the peri-infarct region (Fig. 5A-A $\mathrm{A}^{\prime \prime}$, infarct region outlined by dotted lines in 5A). Robust transgene activation was specific to the ischemic hemisphere as only low levels of transgene activity were observed in the contralateral hemisphere (Fig. 5A). To identify which cell types had RARE-hsp68$L a c Z$ transgene activity following injury, we assayed for specific cell markers within the cerebral cortex. In the non-injury hemisphere, neuronal marker NeuN colocalized with some weakly positive $\beta$-gal expressing cells (Fig. 5B, carets), but we did not observe overlap between $\beta$-gal and the astrocyte marker GFAP (Fig. $5 \mathrm{C}$ ). In the peri-infarct areas in the ischemic hemisphere, strongly labeled $\beta$-galactosidase + cells co-localized with both NeuN (Fig. 5D, carets) and with astrocyte marker GFAP (Fig. 5E, carets). Consistent with analysis of RA levels, the number of $\mathrm{NeuN}+/ \beta$-gal + (Fig. $5 \mathrm{~F}$ ) and GFAP $+/ \beta$-gal + (Fig. 5G) was significantly increased in peri-infarct region as compared to a similar region in the non-ischemic hemisphere ( $\mathrm{p}<0.05)$. We used PDGFra (Fig. 5H) and PDGFr $\beta$ (Fig. 5I) to look for RARE-hsp68-LacZ transgene activity PSCs in the non-lesion and lesion tissue, respectively. Cells in the granule cell layer of the hippocampal dentate gyrus had transgene activity however PDGFr $\alpha+$ PSCs did not co-localize with $\beta$-galactosidase (Fig. $5 \mathrm{H}$, arrows). In the lesion core, PDGFr $\beta+$ PSCs did not have overlapping $\beta$-gal expression (Fig. 5I, carets) but some had closely adjacent expression that appeared to be processes (Fig. 5I, I' open-arrows) possibly $\beta$-galactosidase+ astrocyte or neuronal processes as these cells were present in the same area (Fig. 5I, arrows). Collectively these data show that neurons and astrocytes in the peri-infarct region are responding to RA synthesized by macrophages and PSCs within the lesion core.

\section{Discussion}

PSCs, aka Type "A" pericytes, represent a subset of PDGFr $\beta$-expressing perivascular cells that are activated in the days following a CNS injury, expand in number and contribute significantly to fibrotic scar deposition [9, 11, 31, 48]. The Col1a1-GFP mouse line labels a subset of perivascular cells that fit the primary characteristics of a PSC, most notable of which is expansion and ECM protein deposition following CNS injury. In this study, we first use the unique expression of Col1a1 by PSCs to delineate this population from pericytes and vSMCs in the perivascular space and gain knowledge about this cell type during CNS development. This analysis led to the observation that PSCs, like meningeal fibroblasts, express RA synthesis enzymes Raldh1 and Raldh2. We show that following a focal ischemic injury, increased numbers of Raldh-expressing PSCs and macrophages elevates RA levels that activates RA signaling in peri-infarct neurons and astrocytes. These findings support a novel function for PSCs and macrophages within the infarct core and raise new questions regarding the role of endogenous RA synthesis and signaling following focal brain ischemia.

Our observation that an expanded population of PSCs are, along with macrophages, a source of RA following brain injury resulted from our interest in identifying when and from where Colla1+ PSCs originate. We find that Col1a1+ PSCs are only found in the postnatal brain and we have evidence that they may originate from the meninges. The latter is based on shared expression of meningeal fibroblast markers (e.g. Col1a1, PDGFra, Raldh2, CoupTF2 and PDGFr $\beta$ ) and the expanding distance of PSCs from the meningeal surface during postnatal development. Postnatal appearance of Col1a1+ PSCs contrasts with pericytes and vSMCs that enter the CNS along with blood vessels during prenatal CNS angiogenesis [2] and is another characteristic defining this unique perivascular population. It is also consistent with reports that there is almost no fibrotic scar deposition in the lesion site at P7 following experimental brain injury in 


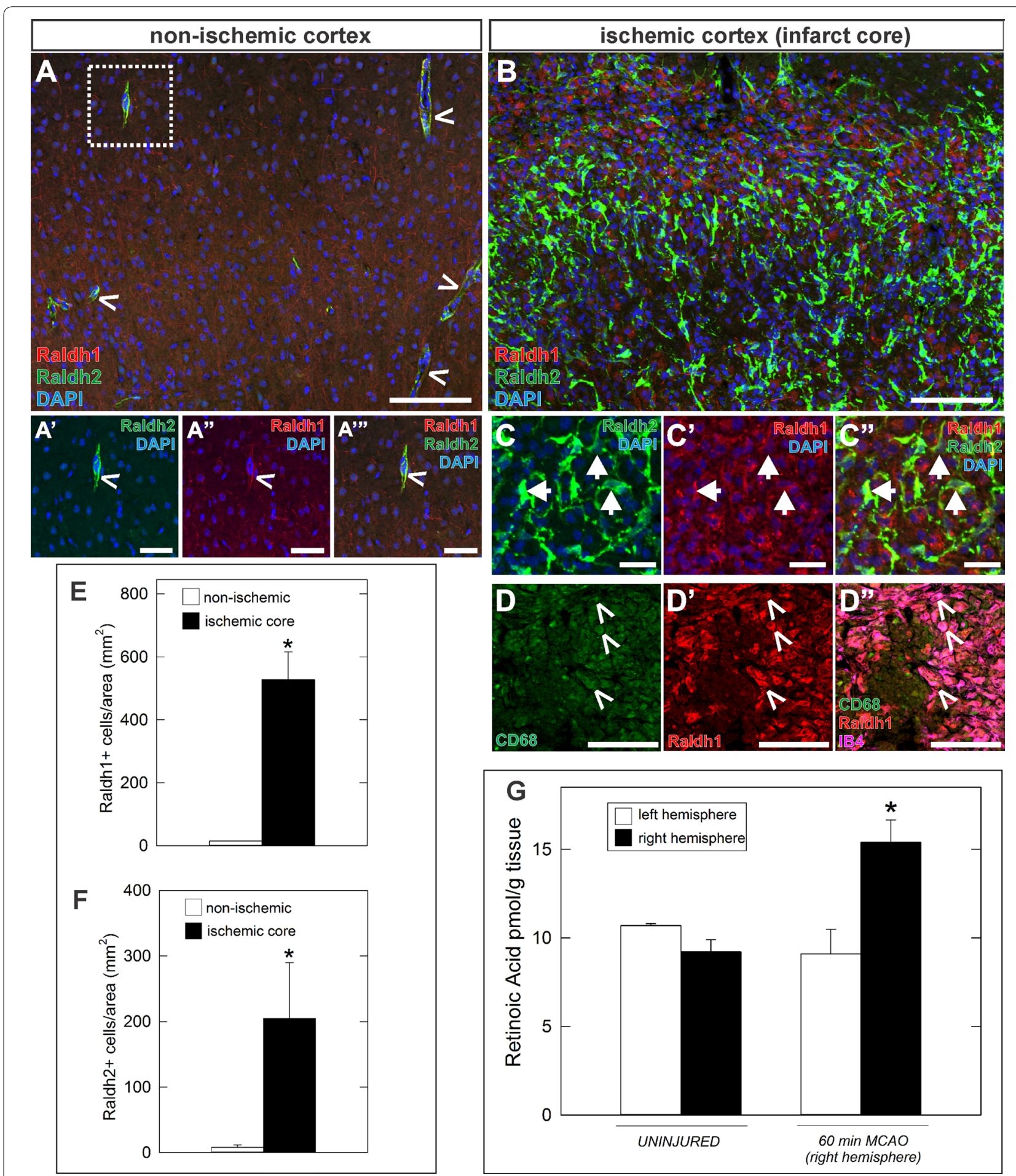

Fig. 4 Elevated RA synthesis and signaling in the ischemic hemisphere. Compared to the uninjured hemisphere (A), the number of cells expressing RA synthesizing enzymes Raldh1 (red) and Raldh2 (green) increases dramatically 7 days following 60 min MCAO (B). Carets in $\mathbf{A}$ and $\mathbf{A}^{\prime}$ insets mark Raldh1+/Raldh2+ PSCs around vessels in non-ischemic cortex. Arrows in C depict Raldh1+/Raldh2+ PSCs in the lesion. Carets in $\mathbf{D}$ indicate CD68+/IB4+ macrophages (green/magenta) express Raldh1 (red) in the lesion core. Graphs depicting quantification of cells expressing Raldh1 (E) and Raldh2 (F) in injured and un-injured hemispheres. Fast LC-MRM ${ }^{3}$ quantification of RA (G) from left and right hemispheres of uninjured and 60 min MCAO (right hemisphere) animals at 7 days post-injury. A minimum of 3 separate animals were analyzed $(n \geq 3)$ and error bars represent SEM. Asterisks indicate statistically significant difference $(p<0.05)$ from uninjured/non-ischemic hemisphere to ischemic hemisphere. DAPI marks nuclei in blue. Scale bars $20 \mu \mathrm{m}(\mathbf{C}), 50 \mu \mathrm{m}\left(\mathbf{A}^{\prime}-\mathbf{A}^{\prime \prime \prime}\right)$, and $100 \mu \mathrm{m}(\mathbf{A}, \mathbf{B}, \mathbf{D})$ 
60 min MCAO - 7 day post-injury: RARE-hsp68-LacZ/+
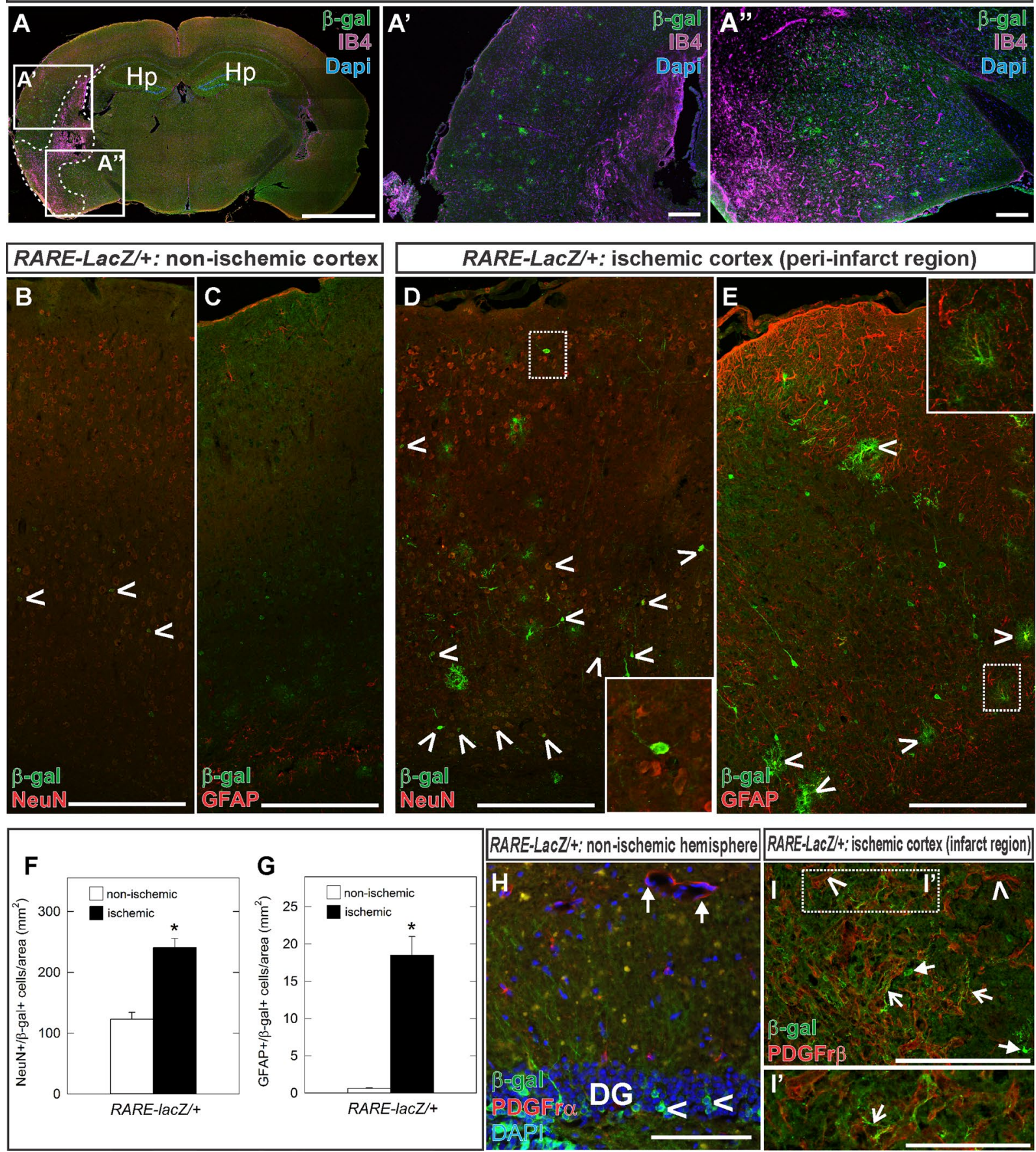

Fig. 5 Assessment of in vivo RA signaling activity. Spatial RA activity assayed using RARE-hsp68-LacZ mouse 7 days post 60 min MCAO injury. Confocal, tile-scan image of $\beta$-galactosidase immunolabeling ( $\beta$-gal, green, $\mathbf{A}$ ) with IB4 (magenta, $\mathbf{A}$ ) at the level of the lesion (outlined with dashed line). $\mathbf{A}^{\prime}$ and $\mathbf{A}^{\prime \prime}$ indicate magnified images in $\mathbf{A}$. Tile stitched confocal images of RA activity in non-ischemic hemispheres ( $\beta$-gal, green, B, C) and ischemic ( $\beta$-gal, green, D-E) with markers for neurons (NeuN, red, carets, B, D), astrocytes (GFAP, red, carets, C, E). Insets are magnified areas with dotted lines in $\mathbf{D}$ and $\mathbf{E}$. Graphs depict quantification of NeuN+/ $\beta$-gal+ neurons $(\mathbf{F})$ and GFAP $+/ \beta$-gal+ astrocytes $(\mathbf{G})$ from non-ischemic and ischemic hemispheres 7 days following a $60 \mathrm{~min} \mathrm{MCAO}(n \geq 3$ and bars represent SEM). Asterisks indicate statistically significant difference $(p<0.05)$ from uninjured/non-ischemic hemisphere and the ischemic hemisphere. PDGFra + PSCs (red) in the non-ischemic cortex did not co-localize with $\beta$-gal (arrows, $\mathbf{H})$ though $\beta$-gal + cells are present in the granule cell layer of the dentate gyrus (DG) (carets, $\mathbf{H})$. $\beta$-gal+ processes (green, I) appear to contact PDGFr $\beta+$ PSCs (red) in the lesion core (open-arrows in $\mathbf{I}$ and $\mathbf{I}^{\prime}$ ) but PDGFr $\beta+$ PSCs do not appear to co-label with $\beta$-gal (caret, I). $\beta$-gal+/ PDGFr $\beta$-negative cell bodies are adjacent to PDGFr $\beta+$ PSCs (arrows, I). DAPI marks nuclei in blue. Scale bars $2 \mathrm{~mm}(\mathbf{A}), 200 \mu \mathrm{m}(\mathbf{B}-\mathbf{E}, \mathbf{I}), 100 \mu \mathrm{m}\left(\mathbf{H}, \mathbf{I}^{\prime}\right)$ 
mice or rats $[19,33]$, a day point when we observe that Col1a1+ PSCs are infrequent. That Col1a1+ PSCs may originate in the meninges and "move" into the perivascular space along arterioles and venules that penetrate the surface of the brain is consistent with the anatomy of the interface between the meninges and perivascular gaps called Virchow-Robin spaces (VRs) (Fig. 6A). VRs start at the point where a vessel in the pial layer of the meninges penetrates the brain surface and runs the length of penetrating arterioles and venules [4]. In this way, VRs are largely continuous with the pial space. VRs may play an important role in interstitial flow, essentially helping to flush cellular debris, notably $\beta$-amyloid, out of the brain parenchyma $[4,38]$. Possibly, VRs also represent an entry point for Col1a1+ meningeal cells from the pial layer of the meninges to enter the perivascular space. Our model is supported by electron microscopy analysis at both the meninges-VRs interface and arterioles within the brain where researchers have characterized pial fibroblasts entering VRs from the meninges $[25,32]$ and surrounding the vSMC layer of arterioles within the brain parenchyma [54].

PSCs that contribute to fibrotic scar formation were, for a long time, mistaken for meningeal fibroblasts that move into the injured CNS after injury-induced damage to the pial basement membrane $[1,51]$. This was based, in part, on the observation that fibrotic cells in the scar were continuous with the meningeal space and expressed markers also expressed by meningeal fibroblasts [5]. Recent lineage tracing using the GLAST-CreErt and Col1a1-GFP lines, however, provide compelling evidence that the fibrotic scar is generated by the resident PSC population and not meningeal fibroblasts moving into injured tissue [13, 48]. Our data provides new insight into why PSCs were erroneously identified as meningeal fibroblasts in that we show that PSCs express many of the same proteins. It is not clear, however, how or why cells might move from the meninges into the perivascular space of the early postnatal brain. It is possible that PSCs in the brain are an artifact of blood vessel development during postnatal brain growth. Conceivable, pial meningeal fibroblasts are "pulled" into the developing brain along the large blood vessel tracts and brain growth around the vessels displaces PSCs deeper into brain structures. It cannot be an entirely passive process, however, since we observe that PSCs are proliferating in the early postnatal brain (data not shown). Also, Colla1+ PSCs increase expression of certain markers like Raldh1, Raldh2, PDGFro, and CRABP1 over time, suggesting that they undergo differentiation in the perivascular space and thus are likely a unique cell type from meningeal fibroblasts. Our analysis also indicates there is heterogeneity in PSCs within the injury site. We observe that only some

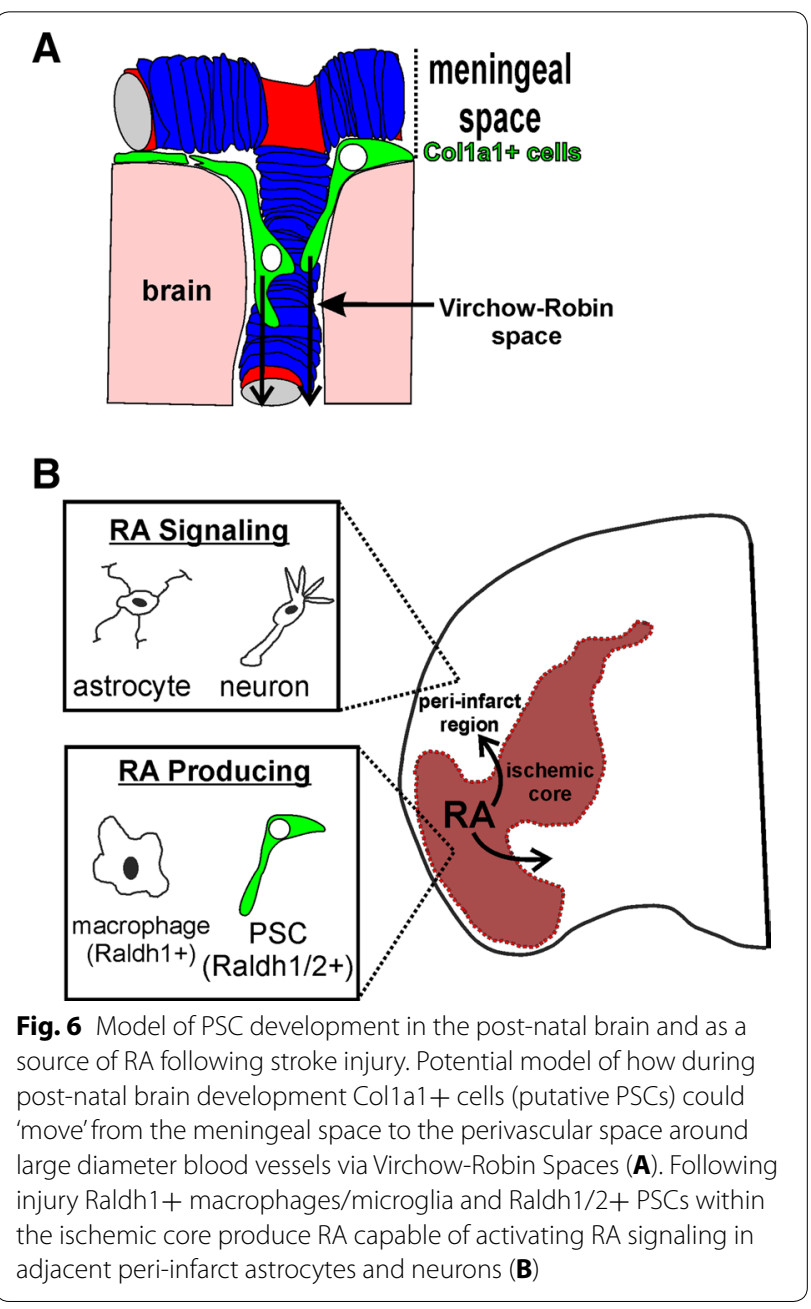

PSCs in the lesion express Raldh1, Raldh2 and CRABP2, suggesting they may be more than one type of PSC. More studies are needed to define different subtypes of PSCs, their origin and function following brain injury.

The meninges are a source of RA for the developing and adult brain $[26,45]$ and we find that Col1a1+ PSCs express RA biosynthesis and signaling proteins. The dramatic expansion of this population, along with infiltration of large numbers of Raldh1-expressing macrophages, following brain ischemia creates a concentrated pool of RA synthesizing cells within the lesion core. Consistent with this, we show that the presence of numerous Raldh-expressing cells correlates with a significant increase in RA levels in the stroke hemisphere at 7 days post-injury. Significantly, when we use the RA signaling reporter, RARE-hsp68-LacZ, we show that elevated RA synthesis in the core stimulates RA signaling activity in peri-infarct neurons and astrocytes at the same time-point. Our data are consistent with transcription profiling of stroke tissue from rat showing 
up-regulation of both Raldh2 and CRABP2 in the ischemic hemisphere following injury [15]. Following spinal cord injury, increased numbers of Raldh $2+$ cells have been reported, along with elevated RA levels and signaling [21, 34, 35]. Considering our characterization of Raldh2+ cells in stroke injury, Raldh2+ cells in spinal cord lesions described in these studies are very likely PSCs. If that is the case, RA synthesis by PSCs may be a common function of this injury-activated cell type following CNS injury.

Our identification of cells in the stroke lesion as a source of RA has implications for how bioactive ligands emanating from the lesion may play a previously unknown role in recovery from ischemic injury. Reports in the stroke literature regarding the effect of exogenous treatment of RA on focal ischemic injury generally conclude that RA is beneficial though different stroke models and exogenous RA treatment regimens were used. Exogenous RA results in a smaller lesion [6, 24], improved blood brain barrier integrity [24], reduced neuroinflammatory response accompanied by decreased hippocampal cell death and improved behavioral recovery [22], and increased neurogenesis and improved neurobehavioral outcomes when coupled with environmental enrichment [42]. Possibly, endogenous RA synthesis mediated by PSCs and macrophages that we describe here has similar effects as reported for exogenous RA in the post-stroke environment. In this way, injury-induced production of RA in the lesion may create a dynamic signaling environment for neurons and glia that could aid in recovery following brain ischemia. Future studies aimed at pharmacologically inhibiting endogenous RA synthesis following stroke injury will provide important insight into the function of endogenous, lesion-derived RA in stroke recovery.

Work thus far on PSCs has focused on their pro-fibrotic function with the idea that therapies to inhibit PSC population expansion would block fibrotic scar deposition and promote neural recovery. Inhibition or reduction of collagen IV and CSPGs (chondroitin sulfate proteoglycans) can attenuate CNS fibrosis [44, 52], however the extent to which that promotes neuronal repair in vivo following injury is not clear [18]. Blocking the TGF $\beta$ pathway following CNS injury decreases ECM deposition and size of the fibrotic scar, but there is not a corresponding recovery of axonal growth $[23,27-29,37]$. These results suggest that blocking fibrotic scar formation is not sufficient for full, functional recovery of the tissue. Importantly, though PSCs contribute to fibrotic scar formation, our work outlined here suggests they may also have a protective function via secretion of bioactive ligands that promote recovery, namely RA. In this way, PSCs may play an unexpected, dual role in regeneration and fibrosis within the injured brain tissue and therapeutic strategies aimed purely at preventing PSC expansion are potentially not ideal.

\section{Conclusions}

Our research supports a dual role for post-injury, activated PSCs where in addition to contributing to fibrosis, PSCs secrete signaling molecule RA. In this way, activated PSCs are potentially capable of influencing of recovery following brain injury.

\begin{abstract}
Abbreviations
$\beta$-gal: $\beta$-galactosidase; CNS: central nervous system; Col1a1: Collagen1a1; CoupTF2: COUP transcription factor 2; CRABP1: Cellular Retinoic Acid Binding Protien 1; CRABP2: Cellular Retinoic Acid Binding Protien 2; CSPG: chondroitin sulfate proteoglycan; DAPI: 4',6-diamidino-2-phenylindole; E16.5: embryonic day 16.5; ECM: extra-cellular matrix; GFAP: glial fibrillary acidic protein; GFP: green fluorescent protein; GLAST: glutamate aspartate transporter; HPLC: high performance liquid chromatography; IB4: isolectin B4; MCAO: middle cerebral artery occlusion; NeuN: neuronal nuclear antigen; PSC: perivascular stromal cell; P0: postnatal day 0; P7: postnatal day 7; P14: postnatal day 14; P21: postnatal day 21; PDGFra: platelet derived growth factor receptor-a; PDGFr $\beta$ : platelet derived growth factor receptor- $\beta$; RA: retinoic acid; Raldh1: retinaldehyde dehydrogenase 1 ; Raldh2: retinaldehyde dehydrogenase 2 ; SEM: standard error of the mean; TGF $\beta$ : transforming growth factor- $\beta$; UV: ultra violet.
\end{abstract}

\section{Authors' contributions}

KKK participated in the study design, data collection, analysis, and drafting the manuscript. AMM participated in data collection and analysis. HG and FS generated stroke animals. JWJ performed the HPLC RA analysis, JY performed the HPLC RA analysis, KP performed the HPLC RA analysis, MAK designed the RA analysis and participated in drafting the manuscript. PH designed the stroke model and participated in drafting the manuscript. JAS conceived and designed the study and participated in drafting the manuscript. All authors read and approved the final manuscript.

\section{Author details}

${ }^{1}$ Department of Pediatrics, Section of Developmental Biology, University of Colorado Denver-Anschutz Medical Campus, 12800 E. 19th Ave MS-8313, Aurora, CO 80045, USA. ${ }^{2}$ Department of Anesthesiology, University of Colorado Denver-Anschutz Medical Campus, Aurora, CO 80045, USA. ${ }^{3}$ Department of Pharmaceutical Sciences, University of Maryland, Baltimore School of Pharmacy, Baltimore, MD 21201, USA. ${ }^{4}$ Department of Pharmacology, University of Colorado Denver-Anschutz Medical Campus, Aurora, CO 80045, USA.

${ }^{5}$ Neuronal Injury Program, University of Colorado Denver-Anschutz Medical Campus, Aurora, USA.

\section{Acknowledgements}

This work was supported funding from the AHA (14BGIA18440006), NIH/ NINDS (R00 NS070920) and Children's Hospital Colorado Research Institute to JAS, NIH/NINDS (R01 NS080851) to PSH, and NIH/NICHD (R01 HD077260), NIH/ NIAID (HHSN272202000046C), and the University of Maryland Mass Spectrometry Center (SOP1841-IQB2014) to MK.

\section{Competing interests}

The authors declare that they have no competing interests.

\section{Animal studies}

Animal studies were performed with strict adherence to The Recommended Guide for Care and Use of Laboratory Animals issued by the National Institutes of Health and all procedures were approved by the Institutional Animal Care and Use Committee at The University of Colorado, Denver-Anschutz Medical Campus [JAS: Animal protocol number: B-99915(07)1D; PSH: B-83311(10) 1E]. All surgery was performed under anesthesia and suffering was minimized. 


\section{Availability of data and materials}

Mouse lines and reagents ('materials') used in this study are commercially available as listed in the "Methods" sections.

\section{Received: 20 October 2015 Accepted: 17 May 2016}

Published online: 15 July 2016

\section{References}

1. Abnet K, Fawcett JW, Dunnett SB. Interactions between meningeal cells and astrocytes in vivo and in vitro. Brain Res Dev Brain Res. 1991;59:187-96

2. Armulik A, Genove G, Betsholtz C. Pericytes: developmental, physiological, and pathological perspectives, problems, and promises. Dev Cell. 2011;21:193-215

3. Boscia F, Esposito CL, Casamassa A, de Franciscis V, Annunziato L, Cerchia $\mathrm{L}$. The isolectin IB4 binds RET receptor tyrosine kinase in microglia. J Neurochem. 2013;126:428-36.

4. Brinker T, Stopa E, Morrison J, Klinge P. A new look at cerebrospinal fluid circulation. Fluids Barriers CNS. 2014;11:10

5. Bundesen LQ, Scheel TA, Bregman BS, Kromer LF. Ephrin-B2 and EphB2 regulation of astrocyte-meningeal fibroblast interactions in response to spinal cord lesions in adult rats. J Neurosci. 2003;23:7789-800.

6. Choi BK, Kim JH, Jung JS, Lee YS, Han ME, Baek SY, Kim BS, Kim JB, Oh SO Reduction of ischemia-induced cerebral injury by all-trans-retinoic acid. Exp Brain Res. 2009;193:581-9.

7. Faulkner JR, Herrmann JE, Woo MJ, Tansey KE, Doan NB, Sofroniew MV. Reactive astrocytes protect tissue and preserve function after spinal cord injury. J Neurosci. 2004;24:2143-55.

8. Fawcett JW, Asher RA. The glial scar and central nervous system repair. Brain Res Bull. 1999;49:377-91.

9. Fernández-Klett F, Potas JR, Hilpert D, Blazej K, Radke J, Huck J, Engel O, Stenzel W, Genové G, Priller J. Early loss of pericytes and perivascular stromal cell-induced scar formation after stroke. J Cereb Blood Flow Metab. 2013;33:428-39.

10. Goodman T, Crandall JE, Nanescu SE, Quadro L, Shearer K, Ross A McCaffery P. Patterning of retinoic acid signaling and cell proliferation in the hippocampus. Hippocampus. 2012;22:2171-83.

11. Goritz C, Dias DO, Tomilin N, Barbacid M, Shupliakov O, Frisen J. A pericyte origin of spinal cord scar tissue. Science. 2011;333:238-42.

12. Graeber MB, Streit WJ, Kiefer R, Schoen SW, Kreutzberg GW. New expression of myelomonocytic antigens by microglia and perivascular cells following lethal motor neuron injury. J Neuroimmunol. 1990;27:121-32.

13. Göritz C, Dias DO, Tomilin N, Barbacid M, Shupliakov O, Frisén J. A pericyte origin of spinal cord scar tissue. Science. 2011;333:238-42.

14. Jones JW, Pierzchalski K, Yu J, Kane MA. Use of fast HPLC multiple reaction monitoring cubed for endogenous retinoic acid quantification in complex matrices. Anal Chem. 2015;87:3222-30.

15. Joseph C, Buga AM, Vintilescu R, Balseanu AT, Moldovan M, Junker H, Walker L, Lotze M, Popa-Wagner A. Prolonged gaseous hypothermia prevents the upregulation of phagocytosis-specific protein annexin 1 and causes low-amplitude EEG activity in the aged rat brain after cerebral ischemia. J Cereb Blood Flow Metab. 2012;32:1632-42.

16. Kane MA, Folias AE, Napoli JL. HPLC/UV quantitation of retinal, retinol, and retinyl esters in serum and tissues. Anal Biochem. 2008;378:71-9.

17. Kane MA, Napoli JL. Quantification of endogenous retinoids. Methods Mol Biol. 2010;652:1-54

18. Kawano H, Kimura-Kuroda J, Komuta Y, Yoshioka N, Li HP, Kawamura K, Li Y, Raisman G. Role of the lesion scar in the response to damage and repair of the central nervous system. Cell Tissue Res. 2012;349:169-80.

19. Kawano H, Li HP, Sango K, Kawamura K, Raisman G. Inhibition of collagen synthesis overrides the age-related failure of regeneration of nigrostriatal dopaminergic axons. J Neurosci Res. 2005:80:191-202.

20. Kelley MH, Ortiz J, Shimizu K, Grewal H, Quillinan N, Herson PS. Alterations in Purkinje cell GABAA receptor pharmacology following oxygen and glucose deprivation and cerebral ischemia reveal novel contribution of $\beta 1$-subunit-containing receptors. Eur J Neurosci. 2013;37:555-63.
21. Kern J, Schrage K, Koopmans GC, Joosten EA, McCaffery P, Mey J. Characterization of retinaldehyde dehydrogenase-2 induction in NG2-positive glia after spinal cord contusion injury. Int J Dev Neurosci. 2007;25:7-16.

22. Kim JH, Yu KS, Jeong JH, Lee NS, Lee JH, Jeong YG, Yoo YC, Han SY. Alltrans-retinoic acid rescues neurons after global ischemia by attenuating neuroinflammatory reactions. Neurochem Res. 2013;38:2604-15.

23. King VR, Phillips JB, Brown RA, Priestley JV. The effects of treatment with antibodies to transforming growth factor beta1 and beta2 following spinal cord damage in the adult rat. Neuroscience. 2004;126:173-83.

24. Kong L, Wang Y, Wang XJ, Wang XT, Zhao Y, Wang LM, Chen ZY. Retinoic acid ameliorates blood-brain barrier disruption following ischemic stroke in rats. Pharmacol Res. 2015;99:125-36.

25. Krahn V. The pia mater at the site of the entry of blood vessels into the central nervous system. Anat Embryol (Berl). 1982;164:257-63.

26. Li H, Wagner E, McCaffery P, Smith D, Andreadis A, Drager UC. A retinoic acid synthesizing enzyme in ventral retina and telencephalon of the embryonic mouse. Mech Dev. 2000;95:283-9.

27. Logan A, Baird A, Berry M. Decorin attenuates gliotic scar formation in the rat cerebral hemisphere. Exp Neurol. 1999;159:504-10.

28. Logan A, Berry M, Gonzalez AM, Frautschy SA, Sporn MB, Baird A. Effects of transforming growth factor beta 1 on scar production in the injured central nervous system of the rat. Eur J Neurosci. 1994;6:355-63.

29. Logan A, Green J, Hunter A, Jackson R, Berry M. Inhibition of glial scarring in the injured rat brain by a recombinant human monoclonal antibody to transforming growth factor-beta2. Eur J Neurosci. 1999;11:2367-74.

30. Maden M. Retinoic acid in the development, regeneration and maintenance of the nervous system. Nat Rev Neurosci. 2007:8:755-65.

31. Makihara N, Arimura K, Ago T, Tachibana M, Nishimura A, Nakamura K, Matsuo R, Wakisaka Y, Kuroda J, Sugimori H, Kamouchi M, Kitazono T. Involvement of platelet-derived growth factor receptor $\beta$ in fibrosis through extracellular matrix protein production after ischemic stroke. Exp Neurol. 2015;264:127-34.

32. Marin-Padilla M. The human brain intracerebral microvascular system: development and structure. Front Neuroanat. 2012;6:38.

33. Maxwell WL, Follows $R$, Ashhurst DE, Berry M. The response of the cerebral hemisphere of the rat to injury. II. The neonatal rat. Philos Trans $R$ Soc Lond B Biol Sci. 1990;328:501-13.

34. Mey J. New therapeutic target for CNS injury? The role of retinoic acid signaling after nerve lesions. J Neurobiol. 2006;66:757-79.

35. Mey J, Morassutti DJ, Brook G, Liu RH, Zhang YP, Koopmans G, McCaffery $P$. Retinoic acid synthesis by a population of NG2-positive cells in the injured spinal cord. Eur J Neurosci. 2005;21:1555-68.

36. Micklem K, Rigney E, Cordell J, Simmons D, Stross P, Turley H, Seed B, Mason D. A human macrophage-associated antigen (CD68) detected by six different monoclonal antibodies. Br J Haematol. 1989;73:6-11.

37. Moon LD, Fawcett JW. Reduction in CNS scar formation without concomitant increase in axon regeneration following treatment of adult rat brain with a combination of antibodies to TGFbeta1 and beta2. Eur J Neurosci. 2001:14:1667-77.

38. Nakada T. Virchow-Robin space and aquaporin-4: new insights on an old friend. Croat Med J. 2014:55:328-36.

39. Napoli JL. Biosynthesis and metabolism of retinoic acid: roles of CRBP and CRABP in retinoic acid: roles of CRBP and CRABP in retinoic acid homeostasis. J Nutr. 1993;123:362-6.

40. Niederreither K, Fraulob V Garnier JM, Chambon P, Dollé P. Differential expression of retinoic acid-synthesizing (RALDH) enzymes during fetal development and organ differentiation in the mouse. Mech Dev. 2002;110:165-71.

41. Okada S, Nakamura M, Katoh H, Miyao T, Shimazaki T, Ishii K, Yamane J, Yoshimura A, Iwamoto Y, Toyama Y, Okano H. Conditional ablation of Stat3 or Socs3 discloses a dual role for reactive astrocytes after spinal cord injury. Nat Med. 2006:12:829-34.

42. Plane JM, Whitney JT, Schallert T, Parent JM. Retinoic acid and environmental enrichment alter subventricular zone and striatal neurogenesis after stroke. Exp Neurol. 2008;214:125-34.

43. Rossant J, Zirngibl R, Cado D, Shago M, Giguère V. Expression of a retinoic acid response element-hsplacZ transgene defines specific domains of transcriptional activity during mouse embryogenesis. Genes Dev. 1991;5:1333-44. 
44. Sharma K, Selzer ME, Li S. Scar-mediated inhibition and CSPG receptors in the CNS. Exp Neurol. 2012;237:370-8.

45. Siegenthaler J, Ashique A, Zarbalis K, Patterson K, Hecht J, Kane M, Folias A, Choe Y, May S, Kume T, Napoli J, Peterson A, Pleasure S. Retinoic acid from the meninges regulates cortical neuron generation. Cell. 2009;139:597-609.

46. Silver J, Miller JH. Regeneration beyond the glial scar. Nat Rev Neurosci. 2004;5:146-56.

47. Slepko N, Levi G. Progressive activation of adult microglial cells in vitro. Glia. 1996;16:241-6.

48. Soderblom C, Luo X, Blumenthal E, Bray E, Lyapichev K, Ramos J Krishnan V, Lai-Hsu C, Park KK, Tsoulfas P, Lee JK. Perivascular fibroblasts form the fibrotic scar after contusive spinal cord injury. J Neurosci. 2013;33:13882-7.

49. Streit WJ, Kreutzberg GW. Lectin binding by resting and reactive microglia. J Neurocytol. 1987;16:249-60.

50. Wagner E, LuOT, Dräger UC. Retinoic acid synthesis in the postnatal mouse brain marks distinct developmental stages and functional systems. Cereb Cortex. 2002;12:1244-53.
51. Wagner FC, Van Gilder JC, Dohrmann GJ. The development of intramedullary cavitation following spinal cord injury: an experimental pathological study. Paraplegia. 1977;14:245-50.

52. Yoshioka N, Hisanaga S, Kawano H. Suppression of fibrotic scar formation promotes axonal regeneration without disturbing blood-brain barrier repair and withdrawal of leukocytes after traumatic brain injury. J Comp Neurol. 2010;518:3867-81.

53. Zarbalis K, Siegenthaler JA, Choe Y, May SR, Peterson AS, Pleasure SJ. Cortical dysplasia and skull defects in mice with a Foxc1 allele reveal the role of meningeal differentiation in regulating cortical development. Proc Natl Acad Sci. 2007;104:14002-7.

54. Zhang ET, Inman CB, Weller RO. Interrelationships of the pia mater and the perivascular (Virchow-Robin) spaces in the human cerebrum. J Anat. 1990;170:111-23.

\section{Submit your next manuscript to BioMed Central and we will help you at every step:}

- We accept pre-submission inquiries

- Our selector tool helps you to find the most relevant journal

- We provide round the clock customer support

- Convenient online submission

- Thorough peer review

- Inclusion in PubMed and all major indexing services

- Maximum visibility for your research

Submit your manuscript at www.biomedcentral.com/submit

() Biomed Central 